\title{
Hard and Soft Tissue Changes After Crestal and Subcrestal Immediate Implant Placement
}

Richard U. Koh, ${ }^{*}$ Tae-Ju Oh, * Ivan Rudek, * Gisele F. Neiva, ${ }^{\dagger}$ Carl E. Misch, ${ }^{\ddagger}$ Edward D. Rothman, $\S$ and Hom-Lay Wang*

Background: The purpose of this study is to assess the influence of the placement level of implants with a laser-microtextured collar design on the outcomes of crestal bone and soft tissue levels. In addition, we assessed the vertical and horizontal defect fill and identified factors that influenced clinical outcomes of immediate implant placement.

Methods: Twenty-four patients, each with a hopeless tooth (anterior or premolar region), were recruited to receive dental implants. Patients were randomly assigned to have the implant placed at the palatal crest or $1 \mathrm{~mm}$ subcrestally. Clinical parameters including the keratinized gingival (KG) width, KG thickness, horizontal defect depth (HDD), facial and interproximal marginal bone levels (MBLs), facial threads exposed, tissue-implant horizontal distance, gingival index (GI), and plaque index (PI) were assessed at baseline and 4 months after surgery. In addition, soft tissue profile measurements including the papilla index, papilla height $(\mathrm{PH})$, and gingival level (GL) were assessed after crown placement at 6 and 12 months post-surgery.

Results: The overall 4-month implant success rate was $95.8 \%$ (one implant failed). A total of 20 of 24 patients completed the study. At baseline, there were no significant differences between crestal and subcrestal groups in all clinical parameters except for the facial MBL $(P=$ $0.035)$. At 4 months, the subcrestal group had significantly more tissue thickness gain (keratinized tissue) than the crestal group compared to baseline. Other clinical parameters (papilla index, PH, GL, PI, and GI) showed no significant differences between groups at any time. A facial plate thickness $\leq 1.5 \mathrm{~mm}$ and HDD $\geq 2 \mathrm{~mm}$ were strongly correlated with the facial marginal bone loss. A facial plate thickness $\leq 2 \mathrm{~mm}$ and HDD $\geq 3$ were strongly correlated with horizontal dimensional changes.

Conclusions: The use of immediate implants was a predictable surgical approach (96\% survival rate), and the level of placement did not influence horizontal and vertical bone and soft tissue changes. This study suggests that a thick facial plate, small gaps, and premolar sites were more favorable for successful implant clinical outcomes in immediate implant placement. J Periodontol 2011;82:1112-1120.

\section{KEY WORDS}

Bone regeneration; dental implants, single-tooth; tooth extraction.

* Department of Periodontics and Oral Medicine, School of Dentistry, University of Michigan, Ann Arbor, MI. $\dagger$ Department of Cariology, Restorative Science and Endodontics, School of Dentistry, University of Michigan.

\# Private practice, Beverly Hills, MI.

$\S$ Center for Statistical Consultation and Research, University of Michigan. $\tau$ n contemporary dentistry, dental implants are considered a standard of care in treating edentulism. The original protocol for dental implants required a healing period of 6 to 8 months after tooth extraction and a stress-free implant healing period of 3 to 6 months for osseointegration. ${ }^{1}$ In the 1970s, immediate implant placement (IIP) was introduced using a step thread, tapered design with round lacuna-like depressions. ${ }^{\| 2}$ The implant was tapped into its final position and retained by a press fit. Newly formed bone filled the lacunae and resulted in stability. ${ }^{2}$ The bioinert dental implant was intended to preserve the alveolar process after tooth extraction. Lazzara ${ }^{3}$ was the first to study IIP in humans by using thread-type implants with expanded polytetrafluoroethylene membranes. Implants were placed $2 \mathrm{~mm}$ subcrestally to allow bone remodeling and osseous regeneration up to the cover screw. The study ${ }^{3}$ concluded that IIP could allow bone preservation at extraction sites. Other I Tübingen implant (FRIALIT-1), Frie-
drichsfeld, Mannhein, Germany. 
studies ${ }^{4,5}$ also suggested immediate placement could preserve the alveolar ridge. However, some recent studies $^{6,7}$ reported IIP failed to preserve the alveolar ridge.

The implant collar design and placement level of the collar may play a role in modulating crestal bone changes. Various implant collar designs, including smooth $^{8}$ and microthread ${ }^{9}$ implant, were studied in immediate placement. However, the laser-microtextured $^{10}$ design has not been studied. In the majority of IIP studies, the dental implants were placed crestally or subcrestally from 1 to $3 \mathrm{~mm} .{ }^{11}$ The rationale for subcrestal placement was to improve esthetics, allow bone regeneration to the coronal portion of implant, and compensate for expected bone resorption. However, the effects of the implant placement level on the crestal bone level were seldom described in the literature.

A laser-microtextured collar" was developed to minimize crestal bone loss on a reverse buttressthreaded implant. ${ }^{\#}$ The $1.5-\mathrm{mm}$ collar contained 8 - and $12-\mu \mathrm{m}$ grooves. It was proposed that $0.7 \mathrm{~mm}$ of the $8-\mu \mathrm{m}$ grooves allowed for soft tissue adhesion, inhibiting epithelial downgrowth, and $0.8 \mathrm{~mm}$ of the 12- $\mu \mathrm{m}$ grooves allowed for bone cell attachment and retention of crestal bone. ${ }^{12} \mathrm{~A}$ human histologic study ${ }^{13}$ demonstrated a true physical connective tissue attachment to the collar under polarized light and scanning electron microscopy. The peri-implant connective tissue acted as a barrier to prevent the apical migration of epithelial attachment. In addition, the reverse-buttress threads provided an excellent primary stability, which was especially critical for IIP.

After implant insertion, a gap between the implant surface and socket walls often results. Depending on the size and location of the gap $(>1.25 \mathrm{~mm}$ on mid-facial and/or $\geq 2.25 \mathrm{~mm}$ on mesial, distal, and mid-lingual locations) bone graft and/or membrane placement may be needed. ${ }^{14}$ Autogenic, allogenic, xenogenic, and alloplastic bone grafts were used in IIP. However, there is no optimal boneaugmentation technique using certain bone grafts and membranes during IIP. ${ }^{11,15}$ A combination of mineralized cancellous and cortical allograft** was introduced. Cancellous chips provide an osteoconductive scaffold, and the cortical chips maintain the space necessary for bone remodeling. This material was recommended by the manufacturer to be used for socket preservation, ridge augmentation, sinus augmentation, and periodontal defects.

The purposes of this randomized pilot study were: 1 ) to assess the influence of the crestal or subcrestal placement of implants with a laser-microtextured collar design on the outcomes of crestal bone and soft tissue levels; 2) to evaluate the effectiveness of mixed cortical and cancellous mineralized bone chips in restoring gaps between the dental implant and surrounding bony walls; and 3) to identify factors influencing clinical outcomes of IIP.

\section{MATERIALS AND METHODS}

\section{Patient Screening and Recruitment}

A power analysis-specific software ${ }^{\dagger \dagger}$ determined that 24 sites were required to detect a $1-\mathrm{mm}$ difference in the marginal bone level (MBL) change between two groups to provide $80 \%$ power, assuming a type I error rate of $5 \%$ and a within-subject variation (SD) of 0.8 $\mathrm{mm}$, as estimated from a previous study. ${ }^{6}$ Twenty-four patients (20 of whom are included in the data analyses) with a single hopeless tooth were recruited from the University of Michigan School of Dentistry. The study was approved by the Institutional Review Board of the University of Michigan (HUM00017289). Patients were included according to the following criteria: 1) $\geq 18$ years of age; 2 ) systemically healthy (American Society of Anesthesiologists I or II); ${ }^{16} 3$ ) with a tooth in the maxillary premolar or anterior region requiring extraction; 4) stable occlusion; 5) adjacent and opposing teeth to the intended site; and 6) a healthy periodontium. The exclusion criteria included: 1) unstable systemic diseases precluding surgical procedures; 2) compromised healing conditions (e.g., uncontrolled diabetes mellitus or human immunodeficiency virus infections); 3) bone disorders (hyperparathyroidism, osteoporosis, or Paget's disease); 4) pregnant or expecting to become pregnant; 5) alcoholism or recreational drug abuse; 6) smoking $\geq 10$ cigarettes per day; 7) long-term (>2 weeks) use of anti-inflammatories, steroids, or bisphosphonates in the past 3 months; 8 ) an O'Leary plaque score $>20 \%$; $^{17}$ 9) severe parafunctional habits; 10) active dental disease (periodontitis, caries, or abscesses); and 11) anatomic limitations (e.g., maxillary sinus involvement). Patients who met the criteria and agreed to participate in the study were asked to read, understand, ask questions, and sign an informed consent form. The study was conducted from June 2008 to October 2009.

\section{Preoperative Procedure}

Upper and lower alginate impressions were taken from each patient for planning and fabricating measurement stents and surgical guides. ${ }^{18}$ Measurement stents and implant surgical guides were fabricated using light-curing acrylic material. ${ }^{\ddagger}$ Eighteen panoramic and standardized periapical radiographs $\S \S$

I Laser-Lok, Biohorizons, Birmingham, AL.

\# Tapered Internal Implant, Biohorizons.

** MinerOss, BioHorizons.

$\dagger \dagger$ nQuery Advisor, Statistical Solutions, Saugus, MA.

\# Triad TruTray, DENTSPLY, York, PA.

$\S \S$ XCP, Rinn Corp., Elgin, IL. 
were taken to assess the adjacent bone-level height and angulation of adjacent teeth. A removable, tooth-supported provisional restoration ${ }^{|l|}$ was fabricated for each patient during the healing phase.

Each patient was randomly assigned (by choosing a letter from a bag) to receive a dental implant 19 ll placed at the palatal crest (crestal) (control) or $1 \mathrm{~mm}$ below the palatal crest (subcrestal) (test) immediately after tooth extraction (Figs. 1A and 1B). The rationale for these placements was based on the expectation of 1 to 2.5 $\mathrm{mm}$ bone resorption after healing according to previous animal and human studies. ${ }^{19,20}$ Thus, implants placed at the crest would have a $0.3-\mathrm{mm}$ polished collar and a $0.7-\mathrm{mm}$ collar with 8 - $\mu \mathrm{m}$ grooves above the crestal bone. Implants placed $1 \mathrm{~mm}$ below the crest would have a polished collar and 8- and $12-\mu \mathrm{m}$ grooves at or below the crest.

\section{Clinical Measurements}

All clinical measurements were done by one calibrated examiner (RUK). The intraexaminer reliability was determined using a weighted $\kappa$ statistic. The weighted $\kappa$ statistic was $\geq 96 \%$ for soft tissue measurements. At baseline and 1, 4, 5, 6, and 12 months postoperatively, oral hygiene and gingival inflammation was assessed on facial aspects of adjacent teeth using the plaque index $(\mathrm{PI})^{21}$ and gingival index $(\mathrm{GI})^{22}$

At baseline, keratinized gingival (KG) thickness was measured using the stent where holes were located at the midpoint on the mid-facial surface of the gingiva (Fig. 1C). A periodontal probe was inserted through the hole perforating the gingiva all the way to the cortical bone. The KG width was measured mid-facially from the gingival margin to the mucogingival junction of the intended extracted tooth. These measurements were repeated at 4 and 12 months.

\section{Surgical Procedure}

All surgeries were performed by the one surgeon $(\mathrm{H}-$ LW) under local anesthesia. ${ }^{\# \#}$ Supracrestal incisions were made around the tooth, and periotomes were used subcrestally to widen the periodontal ligament space. The tooth was atraumatically extracted by avoiding bucco-lingual movements to prevent damage to the labial bone. ${ }^{23}$ The socket was thoroughly curetted and irrigated with sterile saline. An intrabone marrow penetration was performed using curets or rotary instruments to achieve an abundant blood supply. Afterward, the mid-facial and mid-lingual plate thicknesses were measured with a Boley gauge *** at the midpoint of the socket to the gingival margin (Figs. 1D and 1E). The socket width (mid-facial-lingual and mid-mesial-distal) at the alveolar crest and socket depth were measured mid-facially and mid-lingually with a periodontal probe. ${ }^{\dagger \dagger \dagger}$

A surgical guide was used to assist in preparing the osteotomy. The implant was placed at the palatal

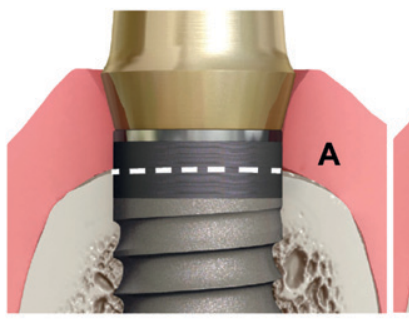

Control (crestal)
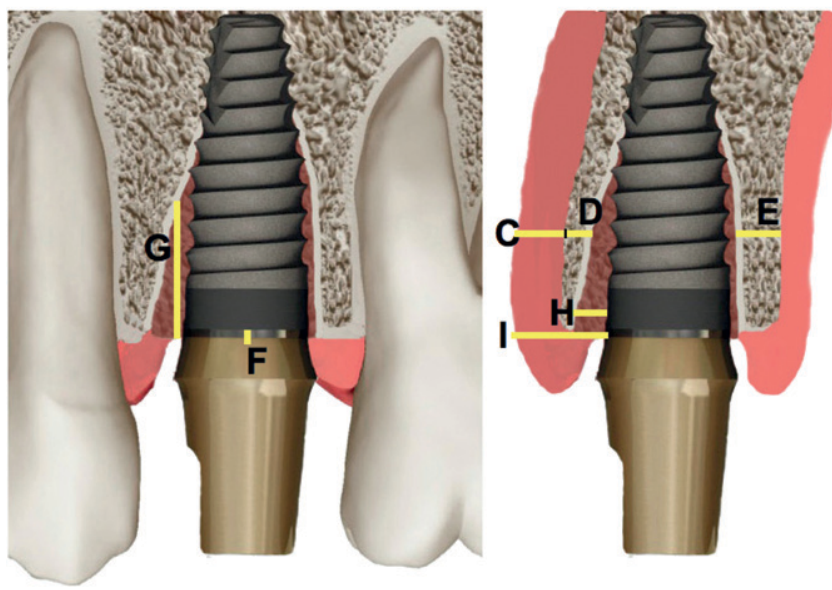

Figure I.

Placement level and clinical measurements. A) Crestal placement. B) Subcrestal placement. C) Facial tissue thickness. D) Facial plate thickness. E) Palatal plate thickness. F) MBL. G) TE. H) HDD. I) T-I.

crest or $1 \mathrm{~mm}$ below the palatal crest. The implant primary stability was achieved and confirmed by tightening a cover screw with rotational and horizontal motions. After implant placement, the following distances were measured using a periodontal probe: 1) the MBL (Fig. 1F) = the vertical distance between the alveolar crest to the fixture level (facial, mesial, and distal); 2) implant threads exposed (TE) (Fig. $1 \mathrm{G})=$ the vertical gap measurement between the implant surface and bone wall (facial mesial and distal); 3 ) the horizontal defect depth (HDD) (Fig. 1H) = the horizontal gap measurement between the implant surface and alveolar crest measured mid-facially; and 4) the tissue-implant horizontal distance (T-I) (Fig. 1I) = the horizontal distance from the keratinized gingiva to the implant surface.

All sites received a mixture of cortical and cancellous particulated allograft with a particle size ranging from 750 to $1,400 \mu \mathrm{m}^{\text {半 }}$ to fill the defect around the implant. A bioabsorbable collagen wound

\section{Essix, DENTSPLY.}

It Tapered Internal implant, BioHorizon, Birmingham, AL.

\#\# 2\% Xylocaine, Astra Zeneca Pharmaceuticals, Westborough, MA.

*** Iwanson Measuring Device, J.S. Dental, Ridgefield, CT.

$\dagger \dagger \dagger$ UNC Probe, Hu-Friedy, Chicago, IL.

†キ MinerOss, Biohorizons. 
Table I.

\section{Patient Demographic Information}

\begin{tabular}{|c|c|c|c|c|}
\hline Demographic & Total & $\begin{array}{l}\text { Crestal } \\
(n=10)\end{array}$ & $\begin{array}{l}\text { Subcrestal } \\
(n=10)\end{array}$ & $P$ \\
\hline Age (years; mean $\pm S D$ ) & $55.5 \pm 3.3$ & $54.1 \pm 5.7$ & $56.8 \pm 3.5$ & 0.692 \\
\hline \multicolumn{5}{|l|}{$\operatorname{Sex}(n)$} \\
\hline Males & 12 & 8 & 4 & 0.068 \\
\hline Females & 8 & 2 & 6 & \\
\hline \multicolumn{5}{|l|}{ Race (n) } \\
\hline White & 17 & 8 & 9 & 0.383 \\
\hline Black & । & । & 0 & \\
\hline Hispanic & 1 & I & 0 & \\
\hline Asian & 1 & 0 & । & \\
\hline \multicolumn{5}{|l|}{ Location (n) } \\
\hline Premolar & 14 & 7 & 7 & 1.000 \\
\hline Anterior & 6 & 3 & 3 & \\
\hline \multicolumn{5}{|l|}{ Implant dimensions (n) } \\
\hline $3.8 \mathrm{~mm}$ & 14 & 7 & 7 & 1.000 \\
\hline $4.6 \mathrm{~mm}$ & 6 & 3 & 3 & \\
\hline
\end{tabular}

dressing $\S \S \S$ was placed, and flaps were sutured with cross-mattress sutures ${ }^{|l| \mid l}$ but were not intended for primary closure. Achieving the primary closure of extraction sockets can be challenging, and in a previous immediate implant study, ${ }^{24}$ primary flap closure was not the goal. The collagen wound dressing was used to stabilize a blood clot. The patient was instructed to wear the removable, tooth-supported provisional prosthesis.

\section{Postoperative Care and Follow-Up}

All patients received oral and written postoperative instructions. All patients were prescribed pain medication (ibuprofen, $600 \mathrm{mg}$ as needed every 4 to 6 hours) and antibiotics (amoxicillin, $500 \mathrm{mg}$, three times per day for 7 days or azithromycin, $500 \mathrm{mg}$, once a day for 3 days ${ }^{25}$ ). Patients were instructed to rinse with warm salt water for 2 weeks. Patients were seen $\approx 2$ weeks after surgery for suture removal and evaluation and 1 month after surgery. The wound healing index $(\mathrm{WHI})^{26}(1=$ uneventful, 2 = uneventful with slight erythema, and $3=$ poor wound healing) and patient discomfort ( 0 to 10 scale) were assessed at each visit.

\section{Stage II Surgery and Provisional Restoration}

All implants were uncovered by a tissue punch and evaluated. If implant threads were exposed, an intervention surgery consisting of full-thickness reflection and bone grafting was provided to treat the exposure $(\mathrm{n}=3)$. After implant uncovering, clinical measure- ments, including the MBL, HDD, implant TE, and T-I were taken again. A screw-retained acrylic It 1 provisional crown was fabricated and delivered in a non-loading occlusion. The screw hole was filled with temporary restorative material."\#\#

\section{Impressions, Crown Delivery, and Final Assessment}

At the 5-month follow-up, the provisional crown was removed, and an impression coping was placed on the implant. A polyvinylsiloxane $* * *$ final impression was taken for permanent-crown fabrication.

At the 6-month follow-up, a permanent crown was placed, either cement retained $(n=2)$ or screw-retained $(n=18)$, and in functional occlusion. Baseline measurements of the soft tissue profile, including the papilla index, ${ }^{27}$ papilla height, and mid-facial gingival level of the restoration compared to the mid-facial gingival levels of adjacent teeth ${ }^{28}$ were taken.

At the12-month follow-up, the implant success was evaluated. ${ }^{29}$ The papilla index, papilla height, and mid-facial gingival level were recorded again.

\section{Statistical Analyses}

Demographic features of the two groups were compared at baseline using $t$ tests for continuous variables (e.g., age) or Pearson $\chi^{2}$ tests for discrete variables (e.g., sex, race, location, and implant dimensions). Continuous data were presented as mean \pm SE for each clinical parameter. We used paired $t$ tests to contrast continuous 4-month data with baseline data. An independent-samples $t$ test was performed to compare clinical parameters between the two groups at baseline and 4 months. An analysis of covariance (ANCOVA) was used to compare differences between groups with respect to outcomes as well as adjusted for differences in clinical predictors. We measured the degree of association between continuous variables using a Pearson product moment correlation coefficient; for categorical variables, associations were analyzed with the Kendall tau. The significance level for rejection of the null hypothesis was set at $\alpha=$ 0.05. All statistical analyses were performed with statistical software. ${ }^{\dagger \dagger \dagger}$

\footnotetext{
$\S \S \S$ CollaPlug, Zimmer Dental, Carlsbad, CA.

Illl| 4-0 Vicryl, Ethicon Somerville, NJ.

ๆึๆ Alike, GC America, Alsip, IL,

\#\#\# Fermit-N, Ivoclar Vivadent, Buffalo, NY

$* * * *$ Extrude, Kerr, Orange, CA.

$\dagger \dagger \dagger \dagger$ SPSS statistical package version 17.0 for Windows, IBM, Chicago, IL.
} 

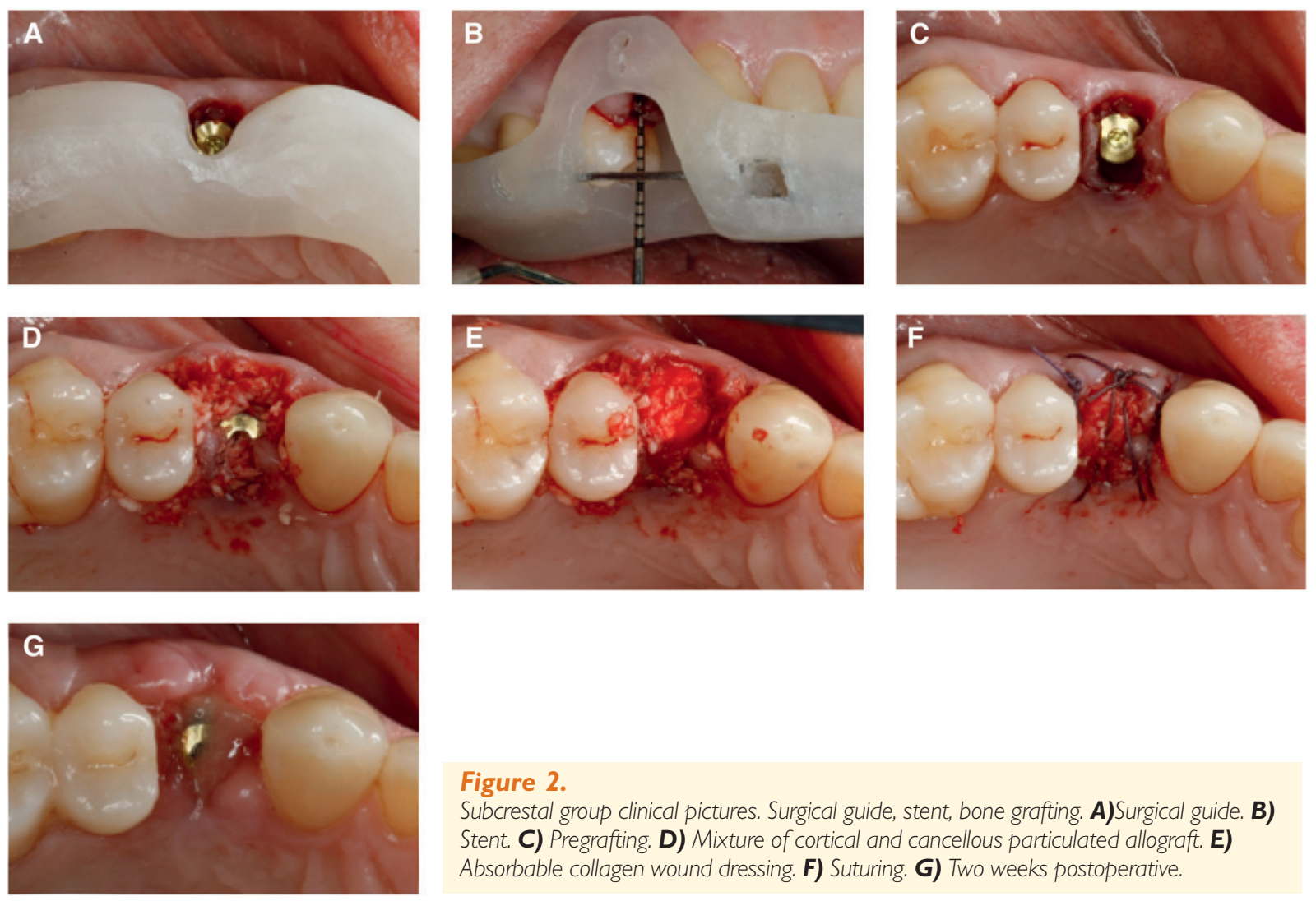

Figure 2.

Subcrestal group clinical pictures. Surgical guide, stent, bone grafting. A)Surgical guide. B)

Stent. C) Pregrafting. D) Mixture of cortical and cancellous particulated allograft. E)

Absorbable collagen wound dressing. F) Suturing. G) Two weeks postoperative.

\section{RESULTS}

\section{Study Population}

A total of 24 patients were enrolled in the study. One patient at the time of immediate placement had a facial dehiscence, another patient had an implant failure, and two patients did not return to complete the study. All four patients were excluded from the final data analyses. Patient demographics are listed in Table 1 . Twenty patients (12 males and eight females) with a mean age of 55.5 years (age range: 21 to 73 years) were included in the data analyses. Each placement-level group (10 each) had seven premolars and three anterior teeth.

\section{Clinical Findings}

A total of 24 immediate implant procedures were performed. Figures 2 and 3 illustrate the cases treated in both groups. The overall survival rate of implant osseointegration at 4 months was $95.8 \%$ (23 of 24 implants).

At baseline, all patients presented with low levels of plaque accumulation (PI) and good gingival health (GI), and no significant differences between groups were noted $(P>0.05)$. There were no significant differences between groups for facial plate thickness, palatal plate thickness, or socket dimensions (Table 2).

The baseline outcome clinical parameters, including KG width, KG thickness, HDD, interproximal MBL,
TE (facial), and T-I were not statistically significantly different between the two groups except for facial MBL $(P=0.035)$; this was due to the level of placement; the subcrestal group was placed $1 \mathrm{~mm}$ below the crestal group. However, at 4 months, there was no difference $(1.6 \pm 0.3 \mathrm{~mm}$ and $1.4 \pm$ $0.3 \mathrm{~mm}$ for crestal and subcrestal groups, respectively). In addition, at 4 months, other outcome clinical parameters, including KG width, KG thickness, HDD, MBL (interproximal), TE (facial) and T-I, were not statistically significantly different between the two groups $(P>0.05)$ (Table 3$)$.

The changes in outcome clinical parameters showed no significant differences in KG width, HDD, facial MBL, interproximal MBL, TE (facial), and T-I between groups $(P>0.05)$ except for KG thickness $(P=0.043)$. The mean increase of KG thickness from baseline to 4 months was $0.7 \pm 0.2 \mathrm{~mm}$ for the crestal group and $1.7 \pm 0.4 \mathrm{~mm}$ for the subcrestal group (Table 3 ).

\section{Soft Tissue Profiles}

There was no statistical difference $(P>0.05)$ in baseline (crown placement), 6 months post-restorative, and the difference between the two time points in soft tissue profiles (including the papilla index, papilla height, and gingival level between crestal and subcrestal groups) (Table 4). 

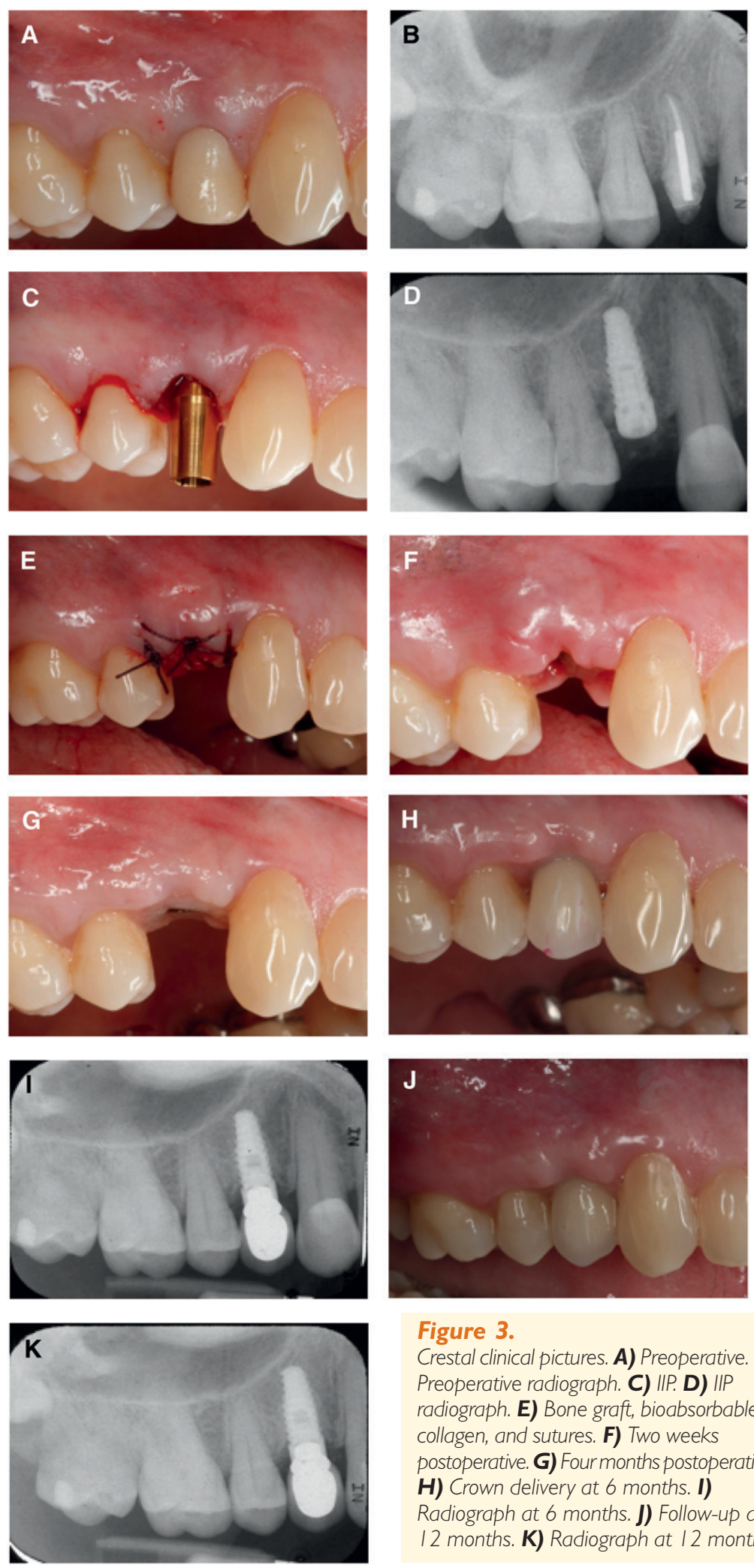

Figure 3.

Crestal clinical pictures. A) Preoperative. B) Preoperative radiograph. C) IIP. D) IIP radiograph. E) Bone graft, bioabsorbable collagen, and sutures. F) Two weeks postoperative. G) Four months postoperative. H) Crown delivery at 6 months. I) Radiograph at 6 months. J) Follow-up at 12 months. K) Radiograph at 12 months.

tistically significantly correlated with the vertical bone loss at facial and distal sites $(P<0.05)$. A facial plate thickness $\leq 1.5 \mathrm{~mm}$ and horizontal defect $\geq 2 \mathrm{~mm}$ were strongly correlated with facial marginal bone loss. In addition, the KG thickness, facial plate thickness, and HDD were statistically significantly correlated with the correction of facial thread exposure $(P<0.038)$. The facial plate thickness, facialpalatal socket dimension, and HDD were each statistically significantly correlated with horizontal dimensional changes $(P<0.02)$. A facial plate thickness $\leq 2 \mathrm{~mm}$ and HDD $\geq 3 \mathrm{~mm}$ were strongly correlated with horizontal dimensional changes. The other factors analyzed (e.g., KG width and mesialdistal socket dimensions) were not statistically correlated with changes.

All patients maintained low levels of plaque accumulation (PI) and good gingival health (GI) throughout the study. There were no significant differences between groups at baseline and 4 months $(P>0.05)$. There were also no significant differences in the $\mathrm{WHI}$ and patient discomfort index ${ }^{30}$ between groups at follow-ups $(P>0.05)$.

\section{DISCUSSION}

IIP has become a popular technique to replace hopeless teeth. In the present study, all dental implants had an initial primary stability, and only one implant failed before implant loading. The overall implant survival rate of $96 \%$ was comparable with the survival rates in other IIP studies. ${ }^{31,32}$

The results from this study shows that implants with a laser-microtextured collar design placed either crestally or subcrestally had no statistically significant differences in crestal bone and soft tissue levels. Initially, at baseline, the level of placement was statistically significantly different at facial MBL sites (crestal group: $1.9 \mathrm{~mm}$; subcrestal group: $0.6 \mathrm{~mm}[P=0.035]$ ) but not at interproximal sites. At 4 months, there were no statistically significant

\section{Correlations Between Clinical Parameters on Vertical and Horizontal Changes}

When examining factors that influenced IIP on vertical and horizontal changes, the site location was sta- differences for facial and interproximal MBL between groups. The subcrestal group had $0.8 \mathrm{~mm}$ of facial bone loss, and there was a minimal facial bone gain for the crestal group. Interproximal sites had $\approx 1 \mathrm{~mm}$ of bone 
Table 2.

\section{Baseline Clinical Parameters (mean \pm SE)}

\begin{tabular}{lccc}
\hline Parameters & $\begin{array}{c}\text { Crestal } \\
(n=10)\end{array}$ & $\begin{array}{c}\text { Subcrestal } \\
(n=10)\end{array}$ & $P$ \\
\hline PI & $0.2 \pm 0.1$ & $0.2 \pm 0.1$ & 1.000 \\
GI & $0.1 \pm 0.1$ & $0.2 \pm 0.1$ & 0.556 \\
Facial plate thickness $(\mathrm{mm})$ & $1.1 \pm 0.2$ & $1.4 \pm 0.2$ & 0.622 \\
Palatal plate thickness $(\mathrm{mm})$ & $2.6 \pm 0.2$ & $2.9 \pm 0.4$ & 0.401 \\
\hline Socket dimensions & & & \\
\hline Facial depth $(\mathrm{mm})$ & $16.8 \pm 0.6$ & $16.9 \pm 1.0$ & 0.869 \\
Palatal depth $(\mathrm{mm})$ & $15.1 \pm 0.5$ & $14.5 \pm 0.8$ & 0.261 \\
F-P width $(\mathrm{mm})$ & $8.3 \pm 0.3$ & $8.5 \pm 0.5$ & 0.543 \\
M-D width $(\mathrm{mm})$ & $7.7 \pm 0.3$ & $7.5 \pm 0.5$ & 0.610 \\
\hline
\end{tabular}

$\mathrm{F}-\mathrm{P}=$ facial to palatal; $\mathrm{M}-\mathrm{D}=$ mesial to distal.

remodeling for both groups. Although not significant, the crestal group had more facial thread exposure. This suggested that, when placing an implant with a lasermicrotextured collar design, it should be placed subcrestally to minimize the implant thread exposure. In addition, the implant placement level had no effect on the KG width, horizontal defect fill, or soft tissue profiles except that the subcrestal group gained a statistically significant tissue thickness of $1 \mathrm{~mm}$ compared to the crestal group $(P=0.043)$. This result may be explained by the deeper implant placement which allows for more soft tissue ingrowth.

This study agreed with Araújo et al., ${ }^{7}$ who suggested that immediately placed implants "failed to preserve hard tissue dimensions." Regardless of the laser-microtextured microchannels, interproximal bone remodeling occurred after IIP. Vertical bone changes were less compared to those in the studies by Botticelli et al., ${ }^{19}$ who reported $\approx 2 \mathrm{~mm}$ of interproximal and $3 \mathrm{~mm}$ of facial vertical bone loss, and Araújo et al., ${ }^{7}$ who reported a 2.1-mm facial vertical bone change. These discrepancies could be from: 1) in both studies, full-thickness flaps were elevated to expose bone before implant placement and 2) in Araújo et al., ${ }^{7}$ a $2.8-\mathrm{mm}$ implant smoothcollar was placed subcrestally (versus the $1.5-\mathrm{mm}$ laser-microtextured implant collar design used in present study). It was reported that $2.8-\mathrm{mm}$ smooth collar implants placed $1 \mathrm{~mm}$ subcrestally lost two times the crestal bone height within the first year compared to the crestal placement. ${ }^{8}$ It was reported that a flap reflection resulted in a crestal bone loss of 1 $\mathrm{mm}$, which may have accounted for the differences noted. 33,34
Table 3.

Outcome Clinical Parameters (mean \pm SE)

\begin{tabular}{|c|c|c|c|}
\hline Parameters & Crestal $(n=10)$ & Subcrestal $(n=10)$ & $P$ \\
\hline \multicolumn{4}{|c|}{ KG width (mm) } \\
\hline Baseline & $4.2 \pm 0.4$ & $4.9 \pm 0.5$ & 0.296 \\
\hline 4 Months & $4.4 \pm 0.3$ & $5.0 \pm 0.3$ & 0.162 \\
\hline Difference & $0.2 \pm 0.3$ & $0.1 \pm 0.4$ & 0.850 \\
\hline \multicolumn{4}{|c|}{ KG thickness (mm) } \\
\hline Baseline & $1.7 \pm 0.2$ & $1.4 \pm 0.2$ & 0.229 \\
\hline 4 Months & $2.4 \pm 0.3$ & $3.1 \pm 0.4$ & 0.185 \\
\hline Difference & $0.7 \pm 0.2$ & $1.7 \pm 0.4$ & $0.043 *$ \\
\hline \multicolumn{4}{|l|}{ HDD (mm) } \\
\hline Baseline & $2.9 \pm 0.5$ & $2.4 \pm 0.3$ & 0.427 \\
\hline 4 Months & 0 & 0 & - \\
\hline Difference & $2.9 \pm 0.5$ & $2.4 \pm 0.3$ & 0.427 \\
\hline \multicolumn{4}{|c|}{ MBL (facial) (mm) } \\
\hline Baseline & $1.9 \pm 0.4$ & $0.6 \pm 0.3$ & $0.035^{*}$ \\
\hline 4 Months & $1.6 \pm 0.3$ & $1.4 \pm 0.3$ & 0.682 \\
\hline Difference & $0.3 \pm 0.4$ & $-0.8 \pm 0.6$ & 0.140 \\
\hline \multicolumn{4}{|c|}{ MBL (interproximal) (mm) } \\
\hline Baseline & $0.4 \pm 0.4$ & $-0.2 \pm 0.5$ & 0.387 \\
\hline 4 Months & $1.4 \pm 0.2$ & $0.9 \pm 0.3$ & 0.206 \\
\hline Difference & $-0.9 \pm 0.4$ & $-1.0 \pm 0.4$ & 0.968 \\
\hline \multicolumn{4}{|c|}{ TE (facial) (mm) } \\
\hline Baseline & $7.9 \pm 1.7$ & $8.3 \pm 1.5$ & 0.862 \\
\hline 4 Months & $2.2 \pm 1.2$ & $0.8 \pm 0.4$ & 0.282 \\
\hline Difference & $5.7 \pm 2.5$ & $7.5 \pm 1.6$ & 0.547 \\
\hline \multicolumn{4}{|l|}{ T-I (mm) } \\
\hline Baseline & $5.6 \pm 0.6$ & $5.0 \pm 0.4$ & 0.417 \\
\hline 4 Months & $3.1 \pm 0.4$ & $3.0 \pm 0.2$ & 0.916 \\
\hline Difference & $-2.5 \pm 0.4$ & $-2.0 \pm 0.4$ & 0.359 \\
\hline
\end{tabular}

$-=$ no patient in this category.

* Statistically significant $(P<0.05)$.

In addition to vertical changes, horizontal dimensional changes occurred as well. The horizontal dimensional change for the crestal and subcrestal groups was 2.5 and $2.0 \mathrm{~mm}$, respectively. The horizontal dimensional change differed from that reported by Botticelli et al., ${ }^{6}$ who reported a $56 \%$ overall mean buccal bone resorption. The higher amount of resorption noted in the study of Boticelli et al. ${ }^{6}$ could be from the full-thickness flap reflection and the use of a $2.8-\mathrm{mm}$ smooth collar implant design. ${ }^{6}$ In the present study, a full-thickness flap reflection was avoided to minimize unnecessary bone loss. The facial bone resorption could not be measured in the present study, but the overall horizontal dimensional change was $57 \%$. This implied that a flapless approach for IIP could minimize horizontal facial changes.

A facial plate thickness $\leq 2 \mathrm{~mm}$ and HDD $\geq 3 \mathrm{~mm}$ were strongly correlated with horizontal dimensional 
Table 4.

\section{Comparisons of Soft Tissue Profiles After Crown Placement (mean \pm SE)}

\begin{tabular}{|c|c|c|c|c|c|c|}
\hline \multirow[b]{2}{*}{ Parameters } & \multicolumn{2}{|c|}{ Papilla Index } & \multicolumn{2}{|c|}{ Papilla Height (mm) } & \multicolumn{2}{|c|}{ Gingival Level (mm) } \\
\hline & Crestal & Subcrestal & Crestal & Subcrestal & Crestal & Subcrestal \\
\hline $\begin{array}{l}\text { Baseline (time of crown placement } \\
\text { [6 months post-surgery]) }\end{array}$ & $1.0 \pm 0.2$ & $0.8 \pm 0.3$ & $1.3 \pm 0.3$ & $1.0 \pm 0.3$ & $-0.9 \pm 0.6$ & $-0.3 \pm 0.6$ \\
\hline $\begin{array}{l}6 \text { months after crown placement } \\
(12 \text { months post-surgery) }\end{array}$ & $1.6 \pm 0.2$ & $1.7 \pm 0.2$ & $1.8 \pm 0.2$ & $1.6 \pm 0.3$ & $-0.6 \pm 0.6$ & $0.2 \pm 0.6$ \\
\hline Difference & $0.6 \pm 0.2$ & $0.9 \pm 0.2$ & $0.5 \pm 0.3$ & $0.6 \pm 0.2$ & $0.3 \pm 0.4$ & $0.4 \pm 0.4$ \\
\hline
\end{tabular}

changes. The present study had similar results to those of Ferrus et al., ${ }^{9}$ who reported that a facial bone thickness $\leq 1$ and horizontal gap dimensions $>1 \mathrm{~mm}$ influenced horizontal dimensional changes; however, our analysis was performed at the soft tissue level.

In our study, after placing bone graft material, the site was covered with a bioabsorbable collagen wound dressing (which only lasted $\leq 2$ weeks), and primary closure was not intended. At 4 months, all HDDs or gaps resolved completely, and the vertical defect resolved $72 \%$ to $90 \%$ at 4 months. This implied that the mineralized mixture of cortical and cancellous allograft used in this study is an effective bone graft material for correcting horizontal defects and reducing gap distanced. Also, 12 of the 23 implants were covered by soft tissue from secondary intention healing, and the other $11 \mathrm{im}$ plants had a slight cover-screw exposure. Nonetheless, the slight cover-screw exposure did not affect the treatment outcome; therefore, it was speculated that the primary closure was not necessary for IIP.

Results from this study showed that the correction of facial TE was strongly correlated with the KG thickness, facial plate thickness, and HDD $(P<0.038)$. A facial plate thickness $\leq 1.5 \mathrm{~mm}$ and horizontal defect $\geq 2 \mathrm{~mm}$ significantly affected the vertical bone height on the facial aspect $(P<0.034)$. In the present study, more vertical bone loss occurred in the anterior teeth, thinner facial plate, and large HDD. This might be attributed to the presence of a thin facial plate in the anterior teeth with a mean of $0.5 \mathrm{~mm}$ compared to in premolar teeth with mean of $1.5 \mathrm{~mm}$. Huynh-Ba et al. ${ }^{35}$ reported a mean buccal bone width of 0.8 $\mathrm{mm}$ where $87 \%$ of sites were $\leq 1 \mathrm{~mm}$ and $3 \%$ of sites were $\geq 2 \mathrm{~mm}$. The premolar teeth had a greater facial to palatal socket dimension leading to a wider HDD ( $\geq 3 \mathrm{~mm}$ ), and this may explain why premolars had more horizontal resorption compared to anterior teeth. Thus, premolar sites with HDDs $\geq 3 \mathrm{~mm}$ significantly influenced the horizontal bone resorption $(P<0.028)$.

The present study had some limitations. Four patients did not complete the study, which reduced the study power (24 versus 20 patients), which might have contributed to the non-significant findings. It may be speculated if the sample size was larger, statistical significant differences might have been found. To accurately measure the changed in vertical and horizontal bone levels, a full-thickness flap would have provided better access to visualize the bony architecture. However, this was not performed in an attempt to prevent additional bone loss.

\section{CONCLUSIONS}

Within the limitations of this study, the following conclusions are drawn: 1) IIP is a predictable surgical approach that yielded 96\% survival rate. 2) The level of placement, either crestal or subcrestal, did not influence vertical and horizontal bone and soft tissue changes. 3) For horizontal dimensional changes, the facial plate thickness, site location, facial-palatal socket dimension, and HDD were the primary factors that influenced outcomes.

\section{ACKNOWLEDGMENTS}

The authors thank Mary Layher, research specialist; Amy Lawson, clinical assistant; Cynthia Tsoukalas, clinical assistant; Erika Mischung, clinical assistant; and Lori Jackson, administrative staff, Department of Periodontics and Oral Medicine, University of Michigan School of Dentistry, for their help in the study. This study was partially supported by BioHorizons, Birmingham, Alabama, and the University of Michigan Periodontal Graduate Student Research Fund. Dr. Wang received research support and lecture fees from BioHorizons. Dr. Misch received financial support and lecture fees from BioHorizons. Drs. Koh, Oh, Rudek, Neiva, and Rothman report no conflicts of interest related to this study.

\section{REFERENCES}

1. Brånemark $\mathrm{PI}$, Adell $\mathrm{R}$, Breine $U$, Hansson $\mathrm{BO}$, Lindström J, Ohlsson A. Intra-osseous anchorage of dental prostheses. I. Experimental studies. Scand $J$ Plast Reconstr Surg 1969;3:81-100. 
2. Schulte W, Heimke G. The Tübinger immediate implant. Quintessenz 1976;27:17-23.

3. Lazzara RJ. Immediate implant placement into extraction sites: Surgical and restorative advantages. Int $J$ Periodontics Restorative Dent 1989;9:332-343.

4. Denissen HW, Kalk W, Veldhuis HA, van Waas MA. Anatomic consideration for preventive implantation. Int J Oral Maxillofac Implants 1993;8:191-196.

5. Watzek G, Haider R, Mensdorff-Pouilly N, Haas R. Immediate and delayed implantation for complete restoration of the jaw following extraction of all residual teeth: A retrospective study comparing different types of serial immediate implantation. Int $J$ Oral Maxillofac Implants 1995;10:561-567.

6. Botticelli D, Berglundh T, Lindhe J. Hard-tissue alterations following immediate implant placement in extraction sites. J Clin Periodontol 2004;31:820-828.

7. Araújo MG, Wennström JL, Lindhe J. Modeling of the buccal and lingual bone walls of fresh extraction sites following implant installation. Clin Oral Implants Res 2006;17:606-614.

8. Hämmerle CH, Brägger $U$, Bürgin W, Lang NP. The effect of subcrestal placement of the polished surface of ITI implants on marginal soft and hard tissues. Clin Oral Implants Res 1996;7:111-119.

9. Ferrus J, Cecchinato D, Pjetursson EB, Lang NP, Sanz $M$, Lindhe J. Factors influencing ridge alterations following immediate implant placement into extraction sockets. Clin Oral Implants Res 2010;21:22-29.

10. Shapoff CA, Lahey B, Wasserlauf PA, Kim DM. Radiographic analysis of crestal bone levels around Laser-Lok collar dental implants. Int J Periodontics Restorative Dent 2010;30:129-137.

11. Schwartz-Arad D, Chaushu G. The ways and wherefores of immediate placement of implants into fresh extraction sites: A literature review. J Periodontol 1997;68:915-923.

12. Soboyejo WO, Nemetski B, Allameh S, Marcantonio $\mathrm{N}$, Mercer C, Ricci J. Interactions between MC3T3-E1 cells and textured Ti6Al4V surfaces. J Biomed Mater Res 2002;62:56-72.

13. Nevins M, Nevins ML, Camelo M, Boyesen JL, Kim DM. Human histologic evidence of a connective tissue attachment to a dental implant. Int $J$ Periodontics Restorative Dent 2008;28:111-121.

14. Botticelli D, Berglundh T, Lindhe J. Resolution of bone defects of varying dimension and configuration in the marginal portion of the peri-implant bone. An experimental study in the dog. J Clin Periodontol 2004;31:309-317.

15. Hämmerle CH, Chen ST, Wilson TG Jr. Consensus statements and recommended clinical procedures regarding the placement of implants in extraction sockets. Int J Oral Maxillofac Implants 2004;19(Suppl.):26-28.

16. American Society of Anesthesiologists. ASA physical status classification system. Available at: http://www. asahq.org/clinical/physicalstatus.htm. Accessed September 6, 2007.

17. O'Leary TJ, Drake RB, Naylor JE. The plaque control record. J Periodontol 1972;43:38.

18. Shotwell JL, Billy EJ, Wang HL, Oh TJ. Implant surgical guide fabrication for partially edentulous patients. J Prosthet Dent 2005;93:294-297.

19. Botticelli D, Persson LG, Lindhe J, Berglundh T. Bone tissue formation adjacent to implants placed in fresh extraction sockets: An experimental study in dogs. Clin Oral Implants Res 2006;17:351-358.
20. Iasella JM, Greenwell H, Miller RL, et al. Ridge preservation with freeze-dried bone allograft and a collagen membrane compared to extraction alone for implant site development: A clinical and histologic study in humans. J Periodontol 2003;74:990-999.

21. Löe H, Silness J. Periodontal disease in pregnancy. I. Prevalence and severity. Acta Odontol Scand 1963; 21:533-551.

22. Silness J, Löe H. Periodontal disease in pregnancy. II. Correlation between oral hygiene and periodontal condition. Acta Odontol Scand 1964;22:121-135.

23. Wang HL, Kiyonobu K, Neiva RF. Socket augmentation: Rationale and technique. Implant Dent 2004;13: 286-296.

24. Schulte W, Kleineikenscheidt H, Lindner K, Schareyka R. The Tübingen immediate implant in clinical studies. (in German) Dtsch Zahnarztl Z 1978;33:348-359.

25. EPOCRATES online. Available at: https://online.epocrates. com/home. Accessed September 6, 2007.

26. Huang LH, Neiva RE, Soehren SE, Giannobile WV, Wang HL. The effect of platelet-rich plasma on the coronally advanced flap root coverage procedure: A pilot human trial. $J$ Periodontol 2005;76:1768-1777.

27. Jemt $T$. Regeneration of gingival papillae after singleimplant treatment. Int J Periodontics Restorative Dent 1997; 17:326-333.

28. Lindeboom JA, Tjiook Y, Kroon FH. Immediate placement of implants in periapical infected sites: A prospective randomized study in 50 patients. Oral Surg Oral Med Oral Pathol Oral Radiol Endod 2006;101:705-710.

29. Misch CE, Perel ML, Wang HL, et al. Implant success, survival, and failure: The International Congress of Oral Implantologists (ICOI) Pisa Consensus Conference. Implant Dent 2008;17:5-15.

30. Huskisson EC. Measurement of pain. Lancet 1974;2: 1127-1131.

31. Polizzi G, Grunder $U$, Goené R, et al. Immediate and delayed implant placement into extraction sockets: A 5-year report. Clin Implant Dent Relat Res 2000;2: 93-99.

32. Quirynen M, Van Assche N, Botticelli D, Berglundh T. How does the timing of implant placement to extraction affect outcome? Int $J$ Oral Maxillofac Implants 2007;22(Suppl.):203-223.

33. Wood DL, Hoag PM, Donnenfeld OW, Rosenfeld LD. Alveolar crest reduction following full and partial thickness flaps. J Periodontol 1972;43:141-144.

34. Araújo MG, Sukekava F, Wennström JL, Lindhe J. Ridge alterations following implant placement in fresh extraction sockets: An experimental study in the dog. $J$ Clin Periodontol 2005;32:645-652.

35. Huynh-Ba G, Pjetursson BE, Sanz M, et al. Analysis of the socket bone wall dimensions in the upper maxilla in relation to immediate implant placement. Clin Oral Implants Res 2010;21:37-42.

Correspondence: Dr. Hom-Lay Wang, Department of Periodontics and Oral Medicine, University of Michigan School of Dentistry, 1011 N. University Ave., Ann Arbor, MI 481091078. Fax: 734/936-0374; e-mail: homlay@umich.edu.

Submitted September 1, 2010; accepted for publication December 19, 2010. 